\title{
UMA DISCUSSÃO SOBRE A DIGNIDADE DA PESSOA HUMANA A PARTIR DA ÉTICA DE KANT
}

\author{
José Aparecido Pereira ${ }^{1}$ \\ Pontifícia Universidade Católica do Paraná (PUC/PR) \\ (iD) https://orcid.org/0000-0002-8298-8248
}

\begin{abstract}
RESUMO:
O objetivo fundamental desse artigo consiste em demostrar que a ética de Kant contém elementos teóricos essenciais que possibilitam uma discussão sobre a dignidade da pessoa humana. $\mathrm{O}$ referencial teórico norteador da nossa abordagem será a Fundamentação da metafísica dos costumes. Um aspecto relevante dessa reflexão encontra-se relacionado à segunda formulação do imperativo categórico da qual é possível extrair implicações éticas fundamentais para uma reflexão sobre o ser humano e sua dignidade. $\mathrm{O}$ artigo encontra-se estruturado em torno de dois momentos. Em primeiro lugar, uma abordagem sobre as faculdades que estruturam a concepção de subjetividade em Kant. Em seguida, uma exposição sobre os aspectos mais relevantes da ética kantiana. Será nesse momento que a segunda fórmula do dever e a noção de reino dos fins se constituirão numa interessante chave de leitura para uma reflexão sobre a dignidade da pessoa humana.
\end{abstract}

PALAVRAS-CHAVE: Dever; Pessoa; Dignidade; Razão; Kant.

\section{A DISCUSSION OF THE DIGNITY OF THE HUMAN PERSON FROM THE KANTIAN ETHICS}

\begin{abstract}
:
The fundamental aim of this article is to show that Kant's ethics contains essential theoretical elements that allow a discussion on the dignity of the human person. The guiding theoretical framework of our approach is the metaphysics of morals Grounds. An important aspect of this reflection is related to the second formulation of the categorical imperative which is possible to extract fundamental ethical implications for a reflection on the human being and his dignity. The article is structured around two times. First, an approach to the powers that shape the conception of subjectivity in Kant. Then an exhibition on the most relevant aspects of Kantian ethics. It will be then that the second formula of duty and the kingdom of ends notion will constitute an interesting reading key for a reflection on the dignity of the human person.
\end{abstract}

KEYWORDS: Must; Person; Dignity; Reason; Kant.

\footnotetext{
${ }^{1}$ Doutor em Filosofia. Professor da Pontifícia Universidade Católica do Paraná (PUC/PR), Paraná Brasil. Professor do Programa de Pós-Graduação Stricto Senso em Gestão do Conhecimento nas Organizações, da Unicesumar. Bolsista produtividade e pesquisador do Instituto Cesumar de Ciência, Tecnologia e Inovação (ICETI). E-mail: aparecido.pereira@pucpr.br
} 


\section{Introdução}

O filósofo alemão Immanuel Kant (1724-1804), nascido em Koenigsberg, viveu durante o século XVIII num período de grandes debates e discussões no campo filosófico e científico. Em seu tempo, enquanto a metafísica tradicional ainda se via envolta com inquietações ligadas a Deus, à alma, ao mundo e a outras realidades inteligíveis, Kant fez do homem o fio condutor da sua filosofia na qual o conceito de subjetividade assumirá um papel extremamente relevante. Não ficando indiferente aos grandes debates de sua época, o filósofo tratou de questões relacionadas a diversos campos, tais como, a política, o Direito, a educação e, sobretudo, a ética. Quanto a essa área, o seu grande propósito foi estabelecer um princípio supremo que se constituísse como fundamento para a moralidade.Tendo em vista isso, ele parte da interpretação de que a razão humana é capaz de determinar a vontade e a ação ética sem ser refém ou prisioneira da experiência ou outras inclinações. Assim, a condição fundamental para que se possa fundamentar a ação moral é que ela promova um esvaziamento de todos os pressupostos relacionados ao campo da experiência e da sensibilidade. Para Kant, enquanto a razão pura é capaz de instanciar aprioristicamente os princípios do conhecimento no âmbito fenomênico, por sua vez, a razão pura prática, operando também de modo apriori, é capaz de estabelecer os princípios constitutivos das ações no âmbito da moral. É no contexto dessas discussões que a razão, a vontade e a liberdade assumirão um papel preponderante na ética kantiana, constituindo-se como uma unidade conceitual indissociável e inseparável.

Levando em consideração esses aspectos, a reflexão que pretendemos desenvolver nesse artigo se propõe a responder a seguinte questão: em que medida as noções kantianas de boa vontade, razão, liberdade e dever poderiam fundamentar uma discussão sobre a dignidade da pessoa humana? Cremos que a importância e a relevância dessa discussão se justificam pela atualidade do tema, haja vista que a ética e a dignidade da pessoa humana, constituem-se como condições fundamentais para a edificação de uma sociedade um pouco mais estruturada do ponto de vista da justiça e da igualdade. A abordagem que pretendemos desenvolver nesse artigo encontra-se estruturada em torno de dois grandes momentos. Em primeiro lugar, fazer uma abordagem sobre as faculdades que estruturam a concepção de subjetividade em Kant. Em seguida, faremos uma exposição sobre os aspectos mais relevantes da ética kantiana. Será nesse momento, por exemplo, que trataremos de conceitos, tais como, a razão, a boa vontade, a liberdade e o imperativo categórico. $O$ nosso intento consiste em demonstrar que esses conceitos da ética de Kant possibilitam uma reflexão muito interessante sobre a pessoa humana e sua dignidade.

\section{A subjetividade como elemento constitutivo do pensamento de Kant}

Para Kant, a subjetividade possui uma estrutura que o permite configurar o objeto recebido pela sua percepção através de formas pelas quais o objeto é conhecido e representado. Ela é independente e anterior a experiência, por isso, a priori. Nessa estrutura, encontram-se três faculdades que possibilitam não somente o 
conhecimento e os princípios que fundamentam a moralidade, mas também são elas que garantem ao sujeito um status hegemônico, tornando-se a principal referência para todas as discussões no contexto do pensamento desse filósofo. Assim, o sujeito kantiano é constituído pelas faculdades da sensibilidade, do entendimento e da razão. Tanto a dimensão epistemológica quanto a dimensão ética dependem significativamente do modo como ocorre a relação entre elas. Em relação à sensibilidade, Kant faz alusão do seguinte modo: "a capacidade de receber representações (receptividade), graças à maneira como somos afetados pelos objectos, denomina-se sensibilidade. Por intermédio, pois, da sensibilidade são-nos dados objectos e só ela nos fornece intuições". ${ }^{2}$ Para Kant, essa faculdade tem a função de levar o sujeito a captar o objeto. Isso somente é possível graças às categorias fundamentais que ele chamou de espaço e de tempo. São elas as responsáveis por todas as percepções do mundo externo. Isso significa dizer que a manifestação do objeto sempre ocorre dentro de uma configuração espaço-temporal. Em outras palavras, tudo que se manifesta fora da subjetividade ocorre por meio do espaço e do tempo. Para o filósofo, "o espaço não é mais do que a forma de todos os fenómenos dos sentidos externos, isto é, a condição subjectiva da sensibilidade, única que permite a intuição externa". ${ }^{3}$ Por sua vez, "o tempo não é mais do que a forma do sentido interno, isto é, da intuição de nós mesmos e do nosso estado interior". 4 Assim, tanto o espaço quanto o tempo são propriedades do sujeito e não das coisas ou do objeto.

Já a organização intelectual do conteúdo dado pela sensibilidade através do espaço e do tempo encontra-se sob a responsabilidade de outra faculdade denominada por Kant de entendimento. Ele se refere a essa faculdade do seguinte modo: "o entendimento não é, pois, uma faculdade de intuição. Fora da intuição, não há outro modo de conhecer senão por conceitos. Assim, o conhecimento de todo entendimento, pelo menos do entendimento humano, é um conhecimento por conceitos, que não é intuitivo, mas discursivo". ${ }^{5}$ Conforme Kant, o sujeito transcendental possui uma dimensão intelectual ou racional, cuja função primordial consiste em ordenar ou tornar inteligível o material ou conteúdo fornecido pela sensibilidade. E para fazer isso é necessário um conjunto de categorias, como por exemplo, a causalidade, a substância e assim por diante. O que seriam, então, tais categorias? Para Kant, elas são os elementos internos do entendimento, voltando-se para as intuições espaço-temporal da sensibilidade com o intuito de produzir uma organização intelectual, ou seja, conferi-lhes inteligibilidade. Assim, conforme o pensador, o sujeito nada entenderia se não pudesse colocar sobre as intuições sensíveis algumas regras próprias da atividade do aparato intelectual. Por exemplo: nenhuma intuição sensível seria entendida se o sujeito não lhe aplicasse a categoria da causalidade, isto é, a noção segundo a qual o efeito é oriundo da causa. Ou também a categoria de substância, ou seja, o sujeito relaciona à intuição sensível a noção de que embora ocorra muitas mudanças no fenômeno, sempre existe algo permanente. Dessa forma, é próprio do entendimento manter-se no domínio da

\footnotetext{
${ }^{2}$ KANT, 2013, p. 61

${ }^{3}$ KANT, 2013, p. 67

${ }^{4}$ KANT, 2013, p. 73

${ }^{5}$ KANT, 2013, p. 102
}

PEREIRA, José Aparecido. Uma discussão sobre a dignidade da pessoa humana a partir da ética de Kant. Griot : Revista de 
experiência ou do fenômeno. Portanto, para Kant, o conhecimento é resultado do trabalho em conjunto entre essas duas faculdades, uma vez que o entendimento só pode operar a partir daquilo que se encontra configurado no espaço e no tempo. Dessa forma, é próprio do entendimento manter-se no domínio da experiência ou do fenômeno. Mas o que ocorre se o entendimento ultrapassar o material fornecido pela sensibilidade através do espaço e do tempo? Por que o entendimento é forçado a ir além daquilo que é dado pela experiência, ou seja, o fenômeno? Segundo Kant, isso é obra de uma outra faculdade pertencente ao sujeito denominada de razão.

As reflexões de Kant sobre a razão encontram-se na terceira parte da Crítica da razão pura chamada por ele de Dialética Transcendental. O filósofo faz menção à razão da seguinte maneira: "[...] a denominação de conceito de razão, já previamente indica que este conceito não se deverá confinar nos limites da experiência, porque se refere a um conhecimento do qual todo conhecimento empírico é apenas uma parte". ${ }^{6} \mathrm{O}$ intelecto pode fazer uso dos seus conceitos puros ou categorias, aplicando-os aos dados da sensibilidade ou mantendo-se no horizonte da experiência possível, mas pode também transcender o âmbito fenomênico. Para Kant, a razão se caracteriza justamente por essa propensão natural do nosso intelecto em querer sempre ultrapassar o horizonte da experiência possível. O que significa isso? Significa que a razão colabora para manter juntos a sensibilidade e o entendimento, e coloca uma seqüência para as atividades de ambos: "Todo o nosso conhecimento começa pelos sentidos, daí passa entendimento e termina na razão, acima da qual nada se encontra em nós mais elevado que elabore a matéria da intuição e a traga à mais alta unidade do pensamento". 7

Segundo Kant, essa atividade da razão é possível graças à sua inerente inclinação de querer dar sequência àquilo que é realizado pelo entendimento, forçando uma continuidade no funcionamento das categorias. Por exemplo, se o sujeito atribui causalidade a uma intuição sensível e, com isso, a entende, a razão, por sua vez, como faculdade dos princípios, quer que essa causalidade não pare em um ou dois ou três elos da cadeia causal. Por isso, ela faz com que a cadeia causal remonte até a uma causa primeira. Esse processo leva a própria razão a postular o que Kant chamou de ideias da razão: a alma, o mundo e Deus. Para o filósofo, tais ideias se encontram para além da experiência ou além do domínio físico. Por isso, segundo Kant, "Se o entendimento pode ser definido como a faculdade de unificar os fenômenos mediante regras, a razão é a faculdade de unificar as regras do entendimento mediante princípios. Nunca se dirige, portanto, imediatamente à experiência, nem a nenhum objeto, mas tão só ao entendimento, para conferir ao diverso dos conhecimentos desta faculdade uma unidade a priori, graças a conceitos". ${ }^{8}$ Contudo, essa propensão natural da razão que pressiona as categorias do entendimento a dar sequência para além do fenômeno, resulta na ilusão de chegar à causa primeira, à essência básica e assim por diante. Mas o que aconteceria se a razão tentasse justificar epistemologicamente a existência da alma, do mundo e de Deus? Para Kant, essas ideias da razão dizem respeito a algo ao qual toda

\footnotetext{
${ }^{6}$ KANT, 2013, p. 307

${ }^{7} \mathrm{KANT}, 2013$, p. 298

${ }^{8}$ KANT, 2013, p. 300
}

PEREIRA, José Aparecido. Uma discussão sobre a dignidade da pessoa humana a partir da ética de Kant. Griot : Revista de 
experiência é subordinada, mas jamais são objetos de experiência. Entretanto, a razão, ao buscar a unidade suprema, na tentativa de conhecer um mundo além dos fenômenos, não consegue demonstrar, nem positiva, nem negativamente se a alma é mortal ou imortal e se Deus existe ou não. Ou seja, a razão não pode posicionar-se nem a favor e nem contra a imortalidade da alma e a Deus. Este é o limite da pretensão do conhecimento humano: todo o conhecimento que transcende a experiência é impossível. A razão, com todos os seus princípios a priori, não indica nada mais do que simples objetos de experiência possível. Fora disso nada mais pode ser conhecido. A consequência de toda a discussão kantiana em torno do conhecimento é que a razão humana tem limites, ou seja, não pode fundamentar ou demonstrar as essências últimas da realidade. Mas se a razão não pode se constituir como fundamento para o conhecimento, ela poderá alicerçar outra dimensão importante da existência humana, a saber, a moralidade. É sobre esse assunto que trataremos a seguir.

\section{A ética de Kant e sua relação com a dignidade da pessoa humana}

Na visão de Kant, a razão humana não é somente capaz de fundamentar questões epistemológicas, mas é também capaz de determinar a vontade e, por consequência, a ação moral. Entretanto, para isso, ela não deve estar vinculada à experiência ou a elementos relacionados à sensibilidade. Para ser fundamento da lei moral, a razão deve esvaziar-se de todos os conteúdos empíricos: "As leis morais com seus princípios, em todo conhecimento prático, distinguem-se, portanto, de tudo o mais em que exista qualquer coisa de empírico, e não só se distinguem essencialmente, como também toda a Filosofia moral assenta inteiramente na sua parte pura". ${ }^{9}$ Dessa forma, no entender do filósofo, isso somente será possível se a razão operar de modo a priori. Segundo ele, sob hipótese alguma os princípios empíricos servem de orientação para a moral. ${ }^{10} \mathrm{Um}$ preceito apoiado em princípios empíricos ou relacionado à sensibilidade até pode ser considerado como regra prática, mas jamais deverá ser interpretado como lei moral. Os princípios a priori, fundamentados na razão, é que devem determinar a vontade no agir moral, porque isentos de qualquer interesse ou paixão: "[...] a razão nos foi dada como faculdade prática, isto é, como faculdade que deve exercer influência sobre a vontade, então o seu verdadeiro destino deverá ser produzir uma vontade, não só boa quiçá como meio para outra intenção, mas uma vontade boa em si mesma, para o que a razão era absolutamente necessária". 11

Essa passagem da obra de Kant faz referência explícita a um dos componentes mais fundamentais da sua teoria ética, a saber, o conceito de boa

\footnotetext{
9 KANT 2007, p. 16

10 "[... não se deve buscar em nenhuma outra parte senão numa filosofia pura, e esta (Metafísica) tem que vir portanto em primeiro lugar, e sem ela não pode haver em parte alguma uma Filosofia moral; e aquela que mistura os princípios puros com os empíricos não merece mesmo o nome de filosofia (pois esta distingue-se do conhecimento racional comum exactamente por expor em ciência à parte aquilo que este conhecimento só concebe misturado); merece ainda // muito menos o nome de Filosofia moral, porque, exactamente por este amálgama de princípios, vem prejudicar até a pureza dos costumes e age contra a sua própria finalidade". (KANT, 2007 p. 17)

11 KANT, 2007, p 25.
}

PEREIRA, José Aparecido. Uma discussão sobre a dignidade da pessoa humana a partir da ética de Kant. Griot : Revista de 
vontade. ${ }^{12}$ Dessa forma, ele deve ser considerado como um requisito indispensável para uma compreensão mais profunda da ética kantiana e, por consequência, da dignidade da pessoa humana. Mas qual é o significado de boa vontade na ética de Kant? Uma passagem da Fundamentação da metafísica dos costumes nos permite uma noção interessante sobre o que ele pensava sobre esse conceito: "A boa vontade não é boa por aquilo que promove ou realiza, pela aptidão para alcançar qualquer finalidade proposta, mas tão-somente pelo querer, isto é em si mesma, e, considerada em si mesma, deve ser avaliada em grau muito mais alto do que tudo o que por seu intermédio possa ser alcançado em proveito de qualquer inclinação, ou mesmo, se se quiser, da soma de todas as inclinações". ${ }^{13}$ A partir dessa passagem, podemos dizer que, na interpretação de Kant, o que confere valor moral a uma ação ou a um comportamento não se encontra relacionado às consequências ou a resultados advindos da boa vontade e, sim, a ausência de interesses no próprio querer do agente ético. Com isso, o filósofo procurou evidenciar a tese segundo a qual as ações do sujeito, para estarem no âmbito da moralidade, não podem ter como critério fundamental os seus resultados, mas devem ter como parâmetro a boa vontade, entendida em si mesma como genuinamente boa: "pois o que constitui o valor particular de uma vontade absolutamente boa, valor superior a todo preço, é que o princípio da ação seja livre de todas as influências de motivos contingentes que só a experiência pode fornecer". ${ }^{14}$

Enquanto a razão pura postula os princípios do conhecimento puro e lhe concede leis a priori, a razão prática, trabalhando do mesmo jeito, é geradora dos princípios da moralidade, explicitados de modo resumido no imperativo categórico, fornecendo ao sujeito uma orientação de como ele deve agir. A razão é prática quando tem em si um fundamento suficiente para a determinação da vontade com vista à realização dos seus objetivos. Disso decorre que, além de boa a vontade deve estar na autonomia (autonomia da vontade), constituindo-se como um requisito preponderante para a determinação da moralidade. O contrário, ou seja, a heteronomia da vontade faz com que as regras da moralidade sejam desprovidas de legitimidade, isto é, não têm validade. É por causa disso que Kant estabeleceu uma relação entre vontade, liberdade e razão. Convém dizer que esse aspecto perpassa toda a sua teoria ética. Nas duas passagens a seguir isso aparece bem explicito. Na primeira temos o que segue:

Todo o ser racional que não pode agir senão sob a ideia de liberdade, é por isso mesmo, em sentido prático, verdadeiramente livre, quer dizer, para ele valem todas as leis que estão inseparavelmente ligadas à liberdade, exatamente como se a sua vontade fosse definida como livre em si mesma e de modo válido na filosofia teórica. (KANT, 2007, p. 95).

Por sua vez, na segunda:

12 “Neste mundo, e até também fora dele, nada é possível pensar que possa ser considerado como bom sem limitação a não ser uma só coisa: uma boa vontade". (KANT, 2007, p. 21)

${ }^{13} \mathrm{KANT}, 2007$, p 23

14 KANT, 2007, p. 65

PEREIRA, José Aparecido. Uma discussão sobre a dignidade da pessoa humana a partir da ética de Kant. Griot : Revista de 
Como razão prática ou como vontade de um ser racional, tem de considerar-se a si mesma como livre; isto é, a vontade desse ser só pode ser uma vontade própria sob a ideia da liberdade, e, portanto, é preciso atribuir, em sentido prático, uma tal vontade a todos os seres racionais. (KANT, 2007, p. 96)

Desse modo, devemos ter presente que a vontade, a liberdade e a razão são conceitos indissociáveis na ética de Kant, ou seja, formam um bloco conceitual unitário e não podem ser analisados separadamente. Dessa maneira, a abordagem sobre um pressupõe a referência aos outros. Mas como esses conceitos podem viabilizar uma discussão sobre a dignidade da pessoa humana? Em primeiro lugar, podemos afirmar que esses três conceitos, sobretudo no âmbito da ética, possibilitam a construção de argumentos em defesa da dignidade da pessoa. Isso porque sem eles seria impossível a existência do sujeito ético. Em outras palavras, eles devem ser entendidos e interpretados como elementos constitutivos do agente ético. Disso inferimos que a dignidade da pessoa pressupõe a existência dessas três condições. Ou seja, a dignidade da pessoa humana se funda na razão, na liberdade e na vontade. Assim, pela atividade racional o ser humano, enquanto pessoa e portador de dignidade, não somente se diferencia dos outros seres, conforme já afirmaram muitos filósofos desde a filosofia grega, mas também pelo uso da razão pode "ser consciente de si e dos outros, isto é, ser capaz de reflexão e de reconhecer a existência dos outros como sujeitos éticos iguais a ele". ${ }^{15}$ Por sua vez, a vontade, enquanto um aspecto da natureza humana, pode possibilitar ao homem "[...] a capacidade para controlar e orientar desejos, impulsos, tendências, sentimentos (para que estejam em conformidade com a consciência) e de capacidade para deliberar e decidir entre várias alternativas possíveis". ${ }^{16}$ Portanto, tais atividades também apresentam a pessoa humana como um ser diferenciado em relação aos outros seres, pois somente ela pode exercê-las. A questão da liberdade constitui um aspecto significativo para se pensar a dignidade da pessoa humana. Seguindo a perspectiva kantiana, podemos afirmar que ela nos possibilita pensar o ser humano para além do seu caráter biológico e fisiológico. Isso significa dizer que o homem não se encontra reduzido e determinado somente pelas leis físicas e biológicas que o situam numa esfera determinista na qual tais leis não podem ser violadas. A liberdade, por estar para além do aspecto biológico e transcender o domínio fenomenal e fisiológico, significa a possiblidade até mesmo do ser humano não submeter a sua vontade à razão estando sujeita às influências da sensibilidade.

Mas Kant estabeleceu também uma relação estreita entre a boa vontade e autonomia da vontade a partir do que ele denominou de imperativo categórico que se distingue substancialmente dos imperativos hipotéticos. Tal distinção aparece na Fundamentação da metafísica dos costumes nos seguintes termos: "Os hipotéticos representam a necessidade prática de uma ação possível como meio de alcançar qualquer outra coisa que se quer (ou que é possível que se queira). O imperativo categórico seria aquele que nos representasse uma ação como objetivamente necessária por si mesma, sem relação com qualquer outra finalidade. Como toda a lei prática representa uma ação possível como boa e por isso como necessária para um

15 CHAUI, 2002, p. 337

${ }^{16}$ CHAUI, 2002, p. 337-338

PEREIRA, José Aparecido. Uma discussão sobre a dignidade da pessoa humana a partir da ética de Kant. Griot : Revista de 
sujeito praticamente determinável pela razão, // todos os imperativos são fórmulas da determinação da ação que é necessária segundo o princípio de uma vontade boa de qualquer maneira. No caso de a acho ser apenas boa como meio para qualquer outra coisa, o imperativo é hipotético; se a ação é representada como boa em si, por conseguinte como necessária numa vontade em si conforme à razão como princípio dessa vontade, então o imperativo é categórico". ${ }^{17}$ Essa distinção kantiana entre imperativo hipotéticos e categóricos será crucial para que ele pudesse instituir no campo da moralidade o que é chamado geralmente de máximas do dever.

Assim, Kant apresenta três formulações ou máximas para o imperativo categórico. A que trata o ser humano como fim em si mesmo pode ser interpretada como uma chave de leitura essencial para uma discussão e reflexão sobre a dignidade da pessoa humana. Tal imperativo vem expresso da seguinte maneira: "age de tal modo que consideres a humanidade, tanto em tua pessoa como na pessoa de todos os outros, sempre como fim e nunca como simples meio". ${ }^{18}$ Como é possível estabelecer uma relação entre essa passagem da obra de Kant com a dignidade da pessoa humana? Observemos que nesse imperativo tanto no plano individual (tanto na tua pessoa) quanto em relação ao próximo (na pessoa de todos os outros) o tratamento e a consideração não podem ser visto como um simples meio. Nesse sentido, a ideia fundamental desse imperativo é que por dever devemos respeitar o nosso próprio ser (pessoa) e também a pessoa de outrem como fim em si mesmo. Isso significa que tanto em relação ao eu quanto em relação a outrem a pessoa possui um valor absoluto e, por conta disso, qualquer ação ou atitude que pretenda transformá-la num meio a serviço dos próprios interesses se configuraria como uma ação desprovida de valor moral. Desse forma, a citação nos permite inferir que a sugestão de tratar o ser humano como um fim em si mesmo e não como um meio pelo sujeito ético, justifica-se pelo fato de o tratamento ter como relação fundamental a pessoa humana e sua dignidade como um todo e não como um objeto ou coisa qualquer.

Interpretado dessa maneira, esse imperativo ético proposto por Kant se opõe frontalmente a toda ação cujo objetivo é conceber a pessoa como um simples objeto passível de manipulação, medição e quantificação. Isso significa dizer que a ideia básica desse imperativo é não tornar o ser humano como coisa, ou seja, não estabelecer com ele uma relação de coisificação e de utilidade. Nesse sentido, uma relação fundada nesses parâmetros e critérios constitui a estratégia mais importante para a instituição de uma ação ética cuja finalidade consiste em proteger e preservar a dignidade da pessoa humana. Na verdade, a consideração da pessoa como fim em si mesmo, rechaça a pretensão de interpretá-la como uma coisa de utilidade conveniente, descartável e substituível. Assim, Kant parece nos indicar que um caminho interessante para se reconhecer que o ser humano é dotado de dignidade é vê-lo como único e insubstituível. A partir disso, podemos afirmar que a pessoa humana está acima de qualquer quantificação e objetivação pelo fato de ser fim em si mesmo.

Mas existe, ainda, outra passagem interessante na Fundamentação da metafísica dos costumes de Kant que também nos possibilita uma reflexão sobre a

${ }^{17} \mathrm{KANT}, 2007$, p 50

18 KANT, 2007, p. 69

PEREIRA, José Aparecido. Uma discussão sobre a dignidade da pessoa humana a partir da ética de Kant. Griot : Revista de 
dignidade da pessoa humana. Nela o pensador afirma o seguinte: "no reino dos fins tudo tem um preço ou uma dignidade. Quando uma coisa tem preço, pode-se pôr em vez dela qualquer outra como equivalente; mas quando uma coisa está acima de todo preço, e portanto não permite equivalente, então ela tem dignidade". ${ }^{19}$ Observemos que os elementos essenciais dessa citação encontram-se relacionados ao reino dos fins e à coisa que tem preço e coisa que não tem, embora, a nosso ver, falar da dignidade da pessoa humana se reportando ao termo coisa parece-nos muito estranho. Mas deixando esse inconveniente de lado, a afirmação do filósofo nos permite pensar que, quando ele afirma que a dignidade se encontra acima de todo preço não permitindo o equivalente, isso inevitavelmente induz o nosso pensamento em direção ao ser humano. Portanto, parece-nos que a pessoa humana se encaixa muito bem nessa afirmação de Kant. Sendo assim, se aplicarmos ao ser humano essa passagem, então isso nos autoriza a sustentar que a dignidade da pessoa humana encontra a sua razão de ser no fato de que nenhuma pessoa pode ser vista como mercadoria ou como alguma coisa no sentido comercial que se encontra disponível e que pode ser vendida ou trocada.

Dessa forma, a afirmação de Kant nos faz lembrar uma máxima muito recorrente nos discursos em defesa dos direitos humanos ou em reivindicações cuja finalidade consistem em garantir e preservar direitos já adquiridos: o ser humano não tem preço. É justamente o fato não podermos atribuir-lhe nenhum valor análogo às transações pecuniárias, comerciais e mercadológicas que inferimos a sua dignidade. Em outras palavras, a dignidade da pessoa humana se justifica pelo fato de ela não ter preço. Entendida a partir dessa ótica, a afirmação de Kant constitui um referencial teórico muito interessante não somente para que instituições sociais e Ongs possam estabelecer um processo de conscientização em torno da dignidade e dos direitos da pessoa humana, mas serve também como ponto de partida e pressuposto teórico para o combate a ações e projetos que violam frontalmente tais direitos, tais como, a situações de mulheres em caso de prostituição, o tráfico de seres humanos, trabalho escravo e outras anti-humanistas.

\section{Considerações finais}

A reflexão que procuramos desenvolver no decorrer desse artigo teve como objeto de discussão a dignidade da pessoa humana. O referencial teórico que norteou a nossa abordagem foi, sobretudo, a Fundamentação da metafísica dos costumes de Kant na qual o pensador se propôs a encontrar um fundamento supremo para a moralidade desprovido de qualquer relação com elementos empíricos ou inclinações baseadas nas sensações ou emoções. Ao empreender tal projeto Kant instituiu um princípio que servisse de critério ou parâmetro para que as ações estejam no âmbito da moralidade, isto é, fossem consideradas éticas. Na verdade, a instituição de tal princípio ou fundamento para a moralidade ou levou a, não somente delinear os pressupostos para uma teoria ética em geral, mas também o fez postular um referencial teórico extremamente importante para se discutir aspectos referentes à pessoa humana e sua dignidade. A nosso ver, esse talvez tenha sido o grande legado e

${ }^{19}$ KANT, 2007, p. 77

PEREIRA, José Aparecido. Uma discussão sobre a dignidade da pessoa humana a partir da ética de Kant. Griot : Revista de 
contribuição de Kant quando se inquietou com questões relacionadas à moralidade. Embora sua teoria ética esteja sujeita a muitos questionamentos críticos devido ao seu formalismo e apriorismo exagerados, a tese segundo a qual não tratar a humanidade (pessoa humana) como um simples meio, mas como um fim em si mesmo continua muito atual, pois ela pode jogar luz para muitas situações nas quais os direitos humanos e a dignidade da pessoa humana são constantemente violados e transgredidos ou se encontram refém de projetos e ideologias interesseiros e egoísticos. 


\section{Referências bibliográficas}

CANDIOTTO, C. [Org.]. Ética: abordagens e perspectivas. 2 ed. Curitiba: Champagnat, 2011.

CATTANEO, Mario A. Dignità Umana e pena nella filosofia di Kant. Milano: Giuffrè Editore, 1981.

CHAUI, Marilena. Convite à Filosofia. São Paulo: Editora Ática, 2002.

DELEUZE, G. Para ler Kant. Rio de Janeiro: Francisco Alves Editora, 1976.

GALEFFI, R. A filosofia de Immanuel Kant. Brasília: Universidade de Brasília, 1986.

HECK, José N. A liberdade em Kant. Porto Alegre: Movimento, 1983.

KANT. I. Crítica da razão pura. Lisboa: Fundação Calouste Gulbenkian, 2013

Crítica da razão prática. São Paulo: Martins Fontes, 2008

Fundamentação da metafísica dos costumes. Lisboa: Edições 70, 2007

PATON, H. J. The categorial imperative - a study in Kant's moral philosophy. Philadelphia: University of Pennsylvania Press, 1971.

ROHDEN, Valério. Autonomia do sujeito moral em Kant. Cadernos IHU Idéias. São Leopoldo, 2007.

SEGURA, Sergio Sevilla. Análisis de los imperativos morales en Kant. Valencia: Editora Univ. de Valencia, 1979.

WALKER, Ralph. Kant e a lei moral. Trad. Oswaldo Giacóia Junior. São Paulo: Editora UNESP, 1999.

Autor(a) para correspondência: José Aparecido Pereira, Unicesumar, Av. Guedner, 1610 - Jardim Aclimação, CEP 87050-9000. Maringá - PR, Brasil. aparecido.pereira@pucpr.br 